WSRC-TR-20001-00264, REVISION 0

Key Words

Ion Exchange

Crystalline Silicotitanate,

Plugging

Retention:

Permanent

\title{
Influence of Water Addition on Crystalline Silicotitanate Column Operation
}

M. E. Stallings

J. T. Mills

V. H. Dukes

W. R. Wilmarth

April 26, 2001

Westinghouse Savannah River Company

Savannah River Site

Aiken, SC 29808

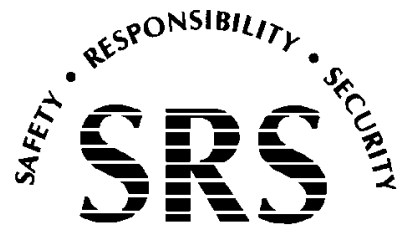

SAVANNAH RIVER SITE 
This document was prepared in conjunction with work accomplished under Contract No.

DE-AC09-96SR18500 with the U.S. Department of Energy.

\section{DISCLAIMER}

This report was prepared as an account of work sponsored by an agency of the United States Government. Neither the United States Government nor any agency thereof, nor any of their employees, makes any warranty, express or implied, or assumes any legal liability or responsibility for the accuracy, completeness, or usefulness of any information, apparatus, product or process disclosed, or represents that its use would not infringe privately owned rights. Reference herein to any specific commercial product, process or service by trade name, trademark, manufacturer, or otherwise does not necessarily constitute or imply its endorsement, recommendation, or favoring by the United States Government or any agency

thereof. The views and opinions of authors expressed herein do not necessarily state or reflect those of the United States Government or any agency thereof.

This report has been reproduced directly from the best available copy.

Available for sale to the public, in paper, from: U.S. Department of Commerce, National Technical Information Service, 5285 Port Royal Road, Springfield, VA 22161, phone: (800)

553-6847, fax: (703) 605-6900, email: orders@ntis.fedworld.gov online ordering: http://www.ntis.gov/ordering.htm

Available electronically at http://www.doe.gov/bridge

Available for a processing fee to U.S. Department of Energy and its contractors, in paper, from: U.S. Department of Energy, Office of Scientific and Technical Information, P.O. Box 62, Oak Ridge, TN 37831-0062, phone: (865 ) 576-8401, fax: (865) 576-5728, email: reports@ adonis.osti.gov 
Key Words:

Ion Exchange

Crystalline Silicotitanate

Retention:

Permanent

Influence of Water Addition on Crystalline Silicotitanate Column Operation

M. E. Stallings

J. T. Mills

V. H. Dukes

W. R. Wilmarth

April 26, 2001

Westinghouse Savannah River Company

Savannah River Site

Aiken, SC 29808

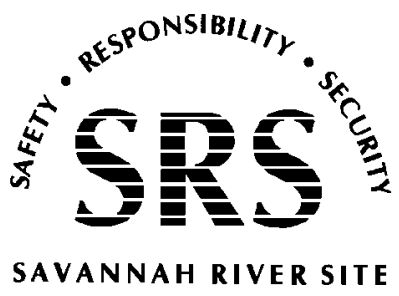

Prepared for the U.S. Department of Energy Under

Contract Number DE-AC09-96SR18500 


\section{REVIEWS AND APPROVALS}

Authors

M. E. Stallings, Waste Processing Technology

Date

J. T. Mills, Waste Processing Technology

Date

V. H. Dukes, Waste Processing Technology

Date

W. R. Wilmarth, Waste Processing Technology

Date

Design Check

F. F. Fondeur, Waste Processing Technology

Date

Management

S. D. Fink, Manager, Liquid Waste Processing Group

Date

D.W. Wester, TFA System Lead

Date

R. Edwards, Manager, Process Engineering

Date

J. T. Carter, Director of Engineering, Salt Processing Project

Date

W. L. Tamosaitis, Manager, Waste Processing Technology Section

Date

Page ii 
TABLE OF CONTENTS

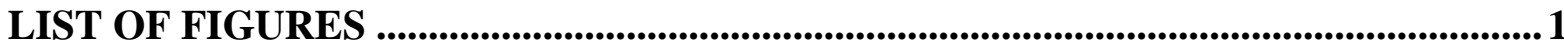

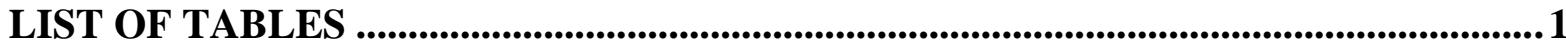

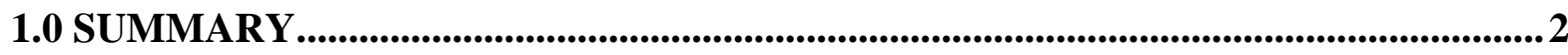

2.0 INTRODUCTION

3.0 EXPERIMENTAL .................................................................................................................

3.1 Preparation of Salt Solution.................................................................................................3

3.2 Batch Test for Aluminum Hydroxide Precipitation ........................................................4

3.3 Column Conditioning .......................................................................................................5

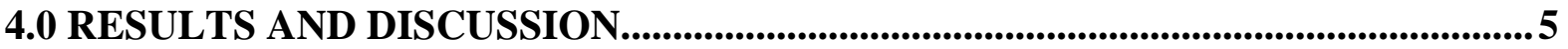

4.1 Results of Batch Tests for Aluminum Precipitation ...........................................................

4.2 Column Test..................................................................................................................6

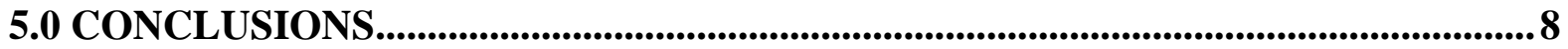

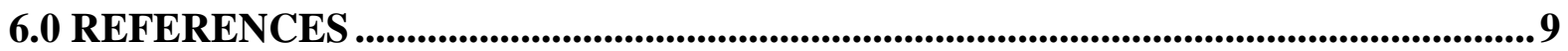

\section{LIST OF FIGURES}

Figure 1. Columns with a fluid head $10 \mathrm{~cm}$ (left) and $4 \mathrm{~cm}$ (right) above the sorbent bed. ..... 6

Figure 2. EDS Spectrum of Post Column CST Particle .......................................................... 8

\section{LIST OF TABLES}

Table 1. Composition of Simulated Waste Solutions ............................................................ 4 


\subsection{SUMMARY}

The proposed use of crystalline silicotitanate (CST) for removal of radiocesium from Savannah River high level waste has received significant research over the past few years. Engineering evaluations of the proposed flow sheet identified several risks. These risks include chemical and thermal stability of the resin, gas generation in the large ion exchange columns, and size reduction and sampling issues for interfacing with the Defense Waste Processing Facility. Research into these potential risks provided information that mitigates or eliminates these risks. Another risk involves the potential to plug the column. One such scenario involves an inadvertent water addition to a cesium-loaded CST column. Under this hypothesis, the water addition changes the $\mathrm{pH}$ in the column and aluminum hydroxide precipitates binding the column. To investigate this risk, we simulated this addition of water in both batch and column tests. Results of this testing showed the following.

- Stepwise additions of water to simulated waste solutions containing $0.32 \mathrm{M}$ aluminum ion concentrations did not produce solid precipitates within 24 hours even at $\mathrm{pH}$ of 10 in batch testing.

- Two column tests at two different liquid head levels using the commercially available CST and "average" Savannah River Site waste simulant followed by water addition did not result in column plugging.

- Following a cesium breakthrough experiment, personnel subjected a column containing the new pre-production batch of CST to water flow and did not observe any evidence of column plugging.

- Finally, two additional column experiments occurred using freshly prepared high nitrate simulant. Water addition to a salt solution-pretreated column of commercially available CST resulted in no evidence of column plugging.

\subsection{INTRODUCTION}

Research efforts in the Salt Processing Project (SPP) include examining an inorganic ion exchange sorbent, crystalline silicotitanate (CST), to remove cesium from high level waste supernatant. This flow sheet uses three 15 -ft (long) by 5 -ft (diameter) ion exchange columns of CST. ${ }^{1}$ Several studies examined the cesium removal efficiencies, along with chemical and thermal stability of the CST. ${ }^{2,3}$

During previous testing of the CST sorbent, several events of column plugging occurred. ${ }^{4}$ Most plugging events related to precipitates containing niobium ${ }^{5}$ or solids resulting from silicon leaching. One incident occurred during experimental cleanup. In that incident, personnel added water to a column loaded with Savannah River Site "average" simulated waste. The column formed a plug and the CST proved difficult to remove from the column. 
The authors interviewed all personnel associated with this earlier plugging event due inadvertent water addition. The single sentence in the letter by Walker provides the only written record of the occurrence and the exact conditions leading to the event remain uncertain. The exact ratio of water to retained waste solution remains unknown. Similarly, we could not determine whether the personnel used de-ionized or untreated tap water. The test did use a sample of IONSIV ${ }^{\circledR}$ IE-911 from a commercially prepared supply (lot \# 89991000009 from UOP). Finally, the test used "average" waste solution prepared by the standard method defined for the project. ${ }^{6}$

An inadvertent addition of water to a fully loaded CST ion exchange column may have detrimental impact to the facility operations. The most likely plugging scenario would result from precipitation of aluminum hydroxide $\mathrm{Al}(\mathrm{OH})_{3}$ caused by a rapid $\mathrm{pH}$ change. Previous studies provide evidence of aluminum hydroxide precipitation including the work by Steele, et al., ${ }^{7}$ and Walker. ${ }^{8}$ The Oak Ridge modeling work showed that gibbsite should form at equilibrium from the high nitrate and average waste compositions used in the SPP research efforts. Additionally, Steele, et al. estimated the maximum soluble aluminate concentration as $0.26 \mathrm{M}$ in the average waste solution. Walker identified several instances where aluminum hydroxide would precipitate from the SRS waste simulants. Walker found that in preparing the published compositions aluminum hydroxide would readily precipitate within 24 hours. Additionally, he observed further reductions in the aluminum concentrations in the average and high nitrate simulants after seeding with gibbsite even after filtering these solids that precipitate soon after preparing the solution. These results indicate a supersaturated condition exists for aluminum in these simulated wastes and potentially in actual tank waste. Therefore, the authors examined water addition to CST columns and assessed for signs of $\mathrm{Al}(\mathrm{OH})_{3}$ precipitation and column operational difficulties.

\subsection{EXPERIMENTAL}

\subsection{PREPARATION OF SA LT SOLUTION}

The tests used the high nitrate and the average salt solutions. High nitrate waste represents the feed composition of dissolved salt cake without blending of supernates. The high nitrate waste also has a slightly higher aluminum concentration than the average waste solution. The average waste solution represents the hypothetical feed composition assuming dissolution of the entire current inventory of salt cake and blending with the total supernate inventory. ${ }^{9}$ Personnel used components shown in Table 1 to prepare $5 \mathrm{~L}$ of the each solution using reagent grade chemicals. 


\subsection{BATCH TEST FOR AL UMINUM HYDROXIDE PRECIPITATION}

The initial testing to examine an inadvertent water addition leading to aluminum hydroxide precipitation occurred in batch tests. The authors performed replicate tests with and without CST present. These batch tests used 150-mL polyethylene bottles placed in an orbital shaker set at $150 \mathrm{rpm}$. For the tests with CST, we added $100 \mathrm{~mL}$ of water and shook by hand and decanted to remove fines. We repeated this process a minimum of three times or until the water was clear of fines.

Next, we added $100 \mathrm{~mL}$ of freshly prepared 3-M sodium hydroxide to each bottle and shook for 1 hour and visually observed for solids. We then removed $50 \mathrm{~mL}$ of supernatant from each beaker and added $50 \mathrm{~mL}$ of the high nitrate salt solution. Personnel performed 7 additions, let set for 15 minutes after each addition, observed for solids, and then repeated the sequence. We let the mixtures stand for 24 hours. In the $\mathrm{pH}$ adjustment step we diluted the high nitrate salt solution by adding water in $25-\mathrm{mL}$ increments until we reached a final $\mathrm{pH}$ reading of 10 . Personnel verified the $\mathrm{pH}$ reading using $\mathrm{pH}$ paper. The final volume of the solution was $100 \mathrm{~mL}$. During each water addition, we visually observed for precipitation.

Table 1. Composition of Simulated Waste Solutions

\section{$\underline{\text { Component }}$}

$\mathrm{Na}^{+}$

$\mathrm{Cs}^{+}$

$\mathrm{K}^{+}$

$\mathrm{OH}^{-}$

$\mathrm{NO}_{3}^{-}$

$\mathrm{NO}_{2}{ }^{-}$

$\mathrm{AlO}_{2}{ }^{-}$

$\mathrm{CO}_{3}{ }^{2-}$

$\mathrm{SO}_{4}{ }^{2-}$

$\mathrm{Cl}^{-}$

$\mathrm{F}^{-}$

$\mathrm{PO}_{4}{ }^{3-}$

$\mathrm{C}_{2} \mathrm{O}_{4}{ }^{2-}$

$\mathrm{SiO}_{3}^{2-}$

$\mathrm{MoO}_{4}{ }^{-}$
Concentration (molar)

Average

5.6

0.00014

0.015

1.91

2.14

0.52

0.31

0.16

0.15

0.025

0.032

0.010

0.008

0.004

0.0002
$\underline{\mathrm{High} \mathrm{NO}}_{3}{ }^{-}$

5.6

0.00014

0.0041

1.17

2.84

0.37

0.32

0.16

0.22

0.040

0.050

0.010

0.008

0.004

0.0002 


\subsection{COLUMN CONDITIONING}

We used borosilicate glass columns (1.5-cm diameters x 10-cm length) for the $\mathrm{pH}-$ adjustment test. We conducted four column tests, one at each liquid level with each of two sources of IONSIV ${ }^{\circledR}$ IE-911. In one column, we maintained a fluid head $10-\mathrm{cm}$ above the sorbent bed while in a second configuration we maintained a fluid head 4-cm above the sorbent bed. See Figure 1 for photos of the column. These configurations represent the range of operating liquid levels typical in previous testing. Since we remain uncertain of the conditions used during the previous plugging event, these conditions should bracket those of the earlier testing.

We obtained $10 \mathrm{~cm}(20 \mathrm{~g})$ of either UOP IONSIV ${ }^{\circledR}$ IE- 911 (Lot \# 999098810005) or a preproduction sample of IE-911, combined with water and back flushed with de-ionized water ( $1 \mathrm{~L}$ of water per $20 \mathrm{~g} \mathrm{CST}$ ) to remove fine particles. The pre-production sample represents material manufactured under a revised protocol to reduce leaching of niobium and silicon. ${ }^{10}$ Then we added the slurry into the ion exchange column drop wise and allowed to settle. To ensure good packing of the sorbent, we tapped the sides of the column.

To initiate the column test we pumped $3 \mathrm{M} \mathrm{NaOH}$ feed from a 1-L bottle to the ion exchange columns at a superficial velocity of $4.1 \mathrm{~cm} / \mathrm{min}$. We flushed each column with a total volume of 1 liter at the rate of $7.2 \mathrm{~mL} /$ minute. Personnel changed the feed solution to both columns from $3 \mathrm{M} \mathrm{NaOH}$ to the salt solution and allowed to flow for a total of 1 liter of liquid. We verified flow rate by the periodic measure of the effluent of each column. At that time, we began the $\mathrm{pH}$ adjustment test by changing the feed solution to tap water and monitored the liquid level above the column and for indications of change and potential solids formation within the column.

We concluded the experiment when the effluent reached a $\mathrm{pH}$ of 10 . Personnel collected spent feed solution and submitted for inductively coupled plasma emission spectroscopy. Researchers evaluated the feed solution to determine the reduction in aluminum content. We collected a sorbent sample and submitted for scanning electron microscope and $\mathrm{x}$-ray diffraction.

\subsection{RESULTS AND DIS CUSSION}

\subsection{RESULTS OF BATCH TESTS FOR ALUMINUM PRECIPITATION}

For the batch tests, regardless of whether the beakers contained CST or not, we saw no evidence of any precipitation. As the solution dilutes to reach a lower $\mathrm{pH}$, the aluminum content also declines. Apparently, the aluminum content reduces sufficiently quickly to avoid rapid formation of solids that might impede flow through a column. 


\subsection{COLUMN TEST}

The first column test used commercially available CST (lot \# 999098810005). Figure 1 shows the experimental configurations. The first test used the configuration that had the fluid head $10-\mathrm{cm}$ above the resin bed. In this column configuration, precipitate gibbsite might form above the sorbent bed in the advent of $\mathrm{pH}$ adjustment after a water addition. The particles could settle upon the bed and plug the fluid flow. After initiating de-ionized water flow to the column, we did not observe any sign of precipitation above the sorbent. Water flowed through the column for a total volume of 1 liter at the rate of $7.2 \mathrm{~mL} /$ minute. The effluent $\mathrm{pH}$ reached 10 at the conclusion of the experiment. No indication of plugging occurred; superficial velocity did not drop nor did the liquid level above the column increase.
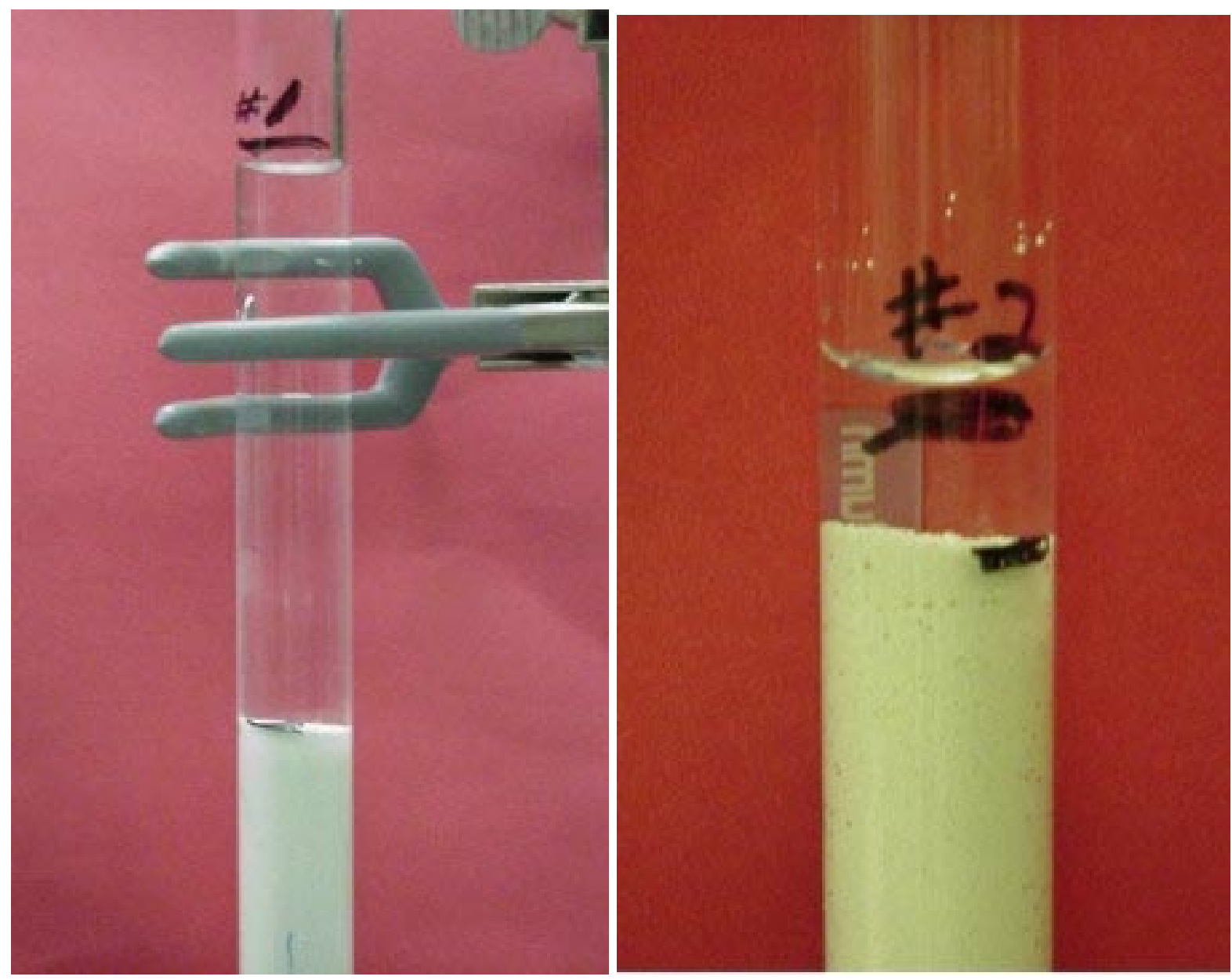

Figure 1. Two $1.5-\mathrm{cm}$ diameter $x 10-\mathrm{cm}$ length ion exchange columns with $10 \mathrm{~cm}$ of UOP IONSIV ${ }^{\circledR}$ IE- 911 (Lot \# 999098810005). A fluid head 10-cm (left) and 4-cm (right) above the resin bed. 
Figure 1 shows a photograph of the second column configuration. In this test, we maintained the liquid level $4-\mathrm{cm}$ above the sorbent. Under these conditions, the $\mathrm{pH}$-adjusting step might occur within the sorbent bed. The second test used identical conditions as the earlier study except for this change in liquid height above the bed. Very similar behavior resulted. We saw no solids above the sorbent. Operational parameters (liquid level and superficial velocity) remained unchanged during the test. No evidence of column plugging occurred.

The third experiment examined two changes to the experimental approach. First, we performed a much longer salt solution treatment prior to adding water. We used a cesiumloaded column. This column contained the UOP- supplied pre-production sample (9098-9). After a standard experiment using 3600-mL average waste, we started de-ionized water flow to this column. Water passed through the column for a total of $1 \mathrm{~L}$ of liquid. As in the previous experiments, we monitored the superficial velocity and the height of the liquid level above the bed. We noted no change in either of the monitored performance indicators. Therefore, the newly supplied CST performed identical to the commercially available resin and the elongated treatment and the presence of cesium did not contribute to column plugging.

The next tests examined two other issues pertaining to potential column plugging. The previous tests used average solution. This supply of the average waste solution had been used in several cesium column runs; therefore, we used cesium nitrate to replenish the cesium concentration of the salt solution. If the aluminum concentration in the initial feed solution had been supersaturated, passing the waste simulant through several ion exchange columns runs may have depleted of the aluminum concentration in the initial feed solution. Therefore, we prepared a fresh waste simulant. For this test, we chose to prepare the high nitrate composition because this simulant has the highest aluminum concentration $(0.32 \mathrm{M}$, as shown in Table 1).

We used both column configurations with the fresh, high nitrate simulant. The tests used the same starting conditions. We washed the IE-911CST to remove fines and conditioned with 3 -M sodium hydroxide for 24 hours. Then we passed 1 liter of the fresh, high nitrate salt solution through the $10-\mathrm{cm} \times 1.5-\mathrm{cm}$ bed of CST. Another difference in these tests involved use of laboratory process water. We followed the same protocol for addition of 1-liter of laboratory process water through the column. The liquid level and superficial velocity did not change during the test.

After the column testing we submitted samples of the IE-911 for x-ray diffraction analyses and energy dispersive spectroscopy (EDS). The measured powder pattern for the IE-911 did not show any discernable peaks other than the base CST. However, the EDS spectrum of the post column resin does not show a significant deposit of aluminum as seen in Figure 2. Aluminum occurs in the spectrum, but it may originate from aluminosilicate precipitation. ${ }^{11}$ 


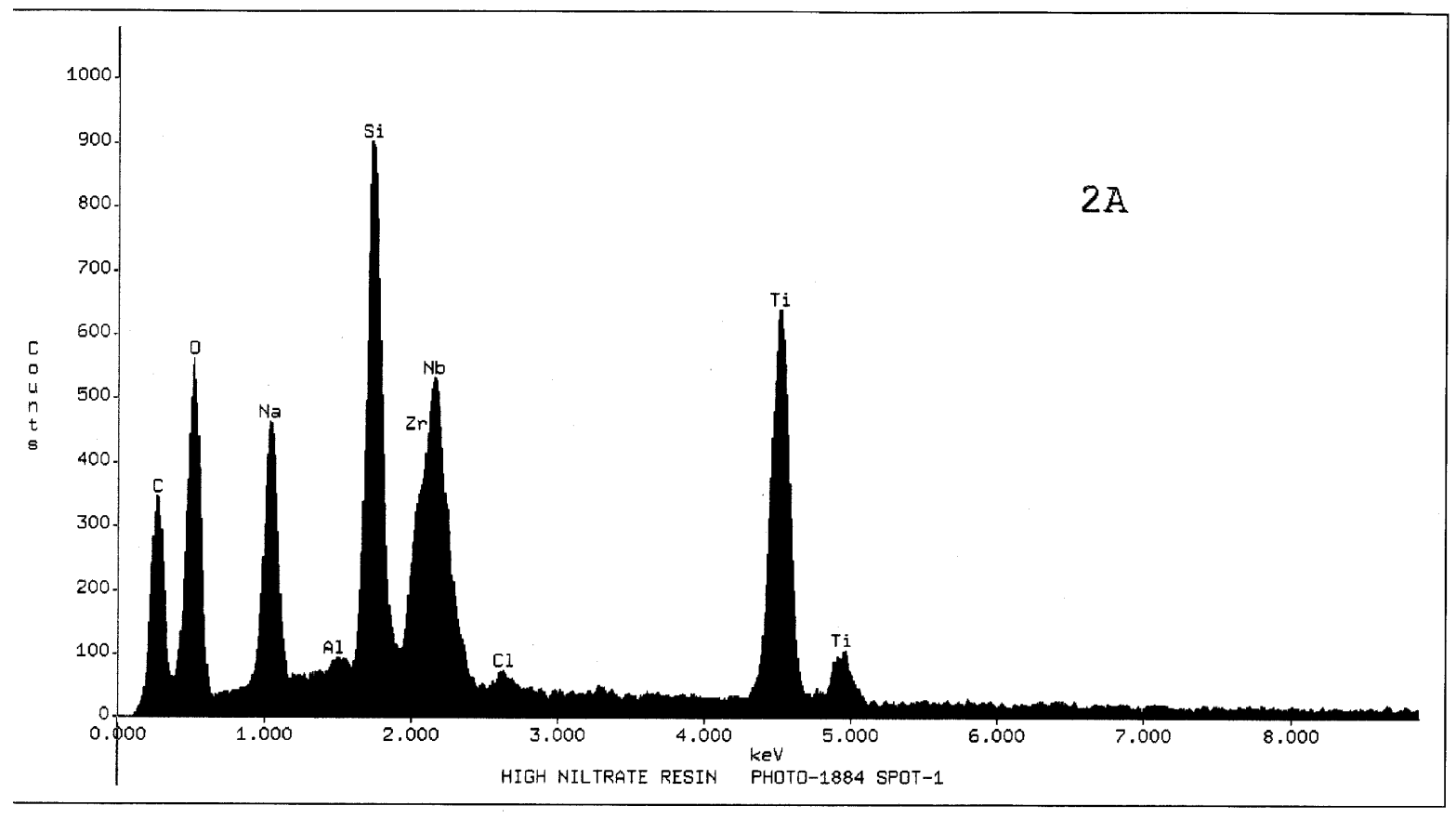

HIGH NILTRATE RESIN PHOTO-1884 SPOT-1

Accelerating Voltage: $25 \mathrm{KeV} \quad$ Take Off Angle: $24.2354^{\circ} \quad$ Live Time: 20.54 seconds $\quad$ Dead Time: 9.883 seconds

\section{Figure 2. EDS Spectrum of Post Column CST Particle}

\subsection{CONCLUSIONS}

The authors investigated the potential to form precipitates in slurries and columns containing simulated waste and CST upon addition of solutions that altered the $\mathrm{pH}$. First we found that stepwise additions of water to simulated waste solutions containing $0.32 \mathrm{M}$ aluminum ion concentrations did not produce solid precipitates even at $\mathrm{pH}$ of $10 \mathrm{in}$ batch testing. In column testing the addition of water to two column tests at two different liquid head levels using the commercially available IE-911 and average waste simulant did not result in column plugging. In another experiment following a cesium breakthrough experiment, a column containing the new pre-production batch of IE-911 also did not lead to column plugging. Lastly, two additional column experiments conducted using freshly prepared high nitrate simulant showed no evidence of plugging upon water addition to a salt solution-pretreated column of IE-911. These tests indicate column plugging does not readily occur upon inadvertent water addition to a column containing simulated waste with elevated concentrations of soluble aluminum. 
This testing involved an initial set of experiments conducted in haste to examine the potential to plug a column of IE-911 upon inadvertent addition of water. The anecdotal occurrence previously reported suggested the plugging would occur rapidly. These tests showed no sign of plugging. The authors recommend further study to examine the risk of plugging and to identify the conditions that favor formation of solids.

\subsection{REFERENCES}

\footnotetext{
${ }^{1}$ R. A. Dimenna, et al., "Bases, Assumptions, and Results of the Flowsheet Calculations for the Decision Phase Salt Disposition Alternatives," WSRC-RP-99-00006, Rev. 2, April 4, 2001.

${ }^{2}$ W. R. Wilmarth and D. D. Walker, "Stability of UOP IONSIV ${ }^{\circledR}$ IE-911 in SRS Simulated Salt Solution at Elevated Temperature and Subjected to Radiation Exposure," WSRC-TR-9900341, September 15, 1999.

${ }^{3}$ P. A. Taylor and C. H. Mattus, "Thermal and Chemical Stability of Crystalline Silicotitanate Sorbent," ORNL/TM-1999/233, October 1999.

${ }^{4}$ D. D. Walker, "Crystalline Silicotitanate Column Plugging Incidents," SRT-LWP-200000136, August 22, 2000.

${ }^{5}$ D. D. Walker, et al., "Cesium Removal from Savannah River Site Radioactive Waste using Crystalline Silicotitanate (IONSIV ${ }^{\circledR}$ IE-911), WSRC-TR-99-00308, Rev. 0, September 18, 1999.

${ }^{6}$ D. D. Walker, "Preparation of Simulant Waste Solutions," WSRC-TR-99-00116, April 15, 1999.

${ }^{7}$ W. F. Steele, C. F. Weber, and D. A. Bostick, "Waste and Precipitation Issues," ORNL/TM2000/348, January 2001.

${ }^{8}$ D. D. Walker, "Stability and Solubility Tests with SRS Simulated Wastes," WSRC-TR2000-00273, November 6, 2000.

${ }^{9}$ D. D Walker, W. D. King, D. P. Diprete, L. L. Tovo, D. T. Hobbs, and W. L. Wilmarth, "Cesium Removal from Simulated SRS High-Level Waste using Crystalline Silicotitanate, " WSRC-TR-98-00344, Rev. 1, October 16, 1998.

${ }^{10}$ W. R. Wilmarth, D. D. Walker, F. F. Fondeur, S. D. Fink, M. Nyman, J. Krumhansel, J. T. Mills, V. H. Dukes, and B. H. Croy, "Examination of Pre-Production Samples of UOP IONSIV $^{\circledR}$ IE-910 and IE-911,” WSRC-TR-2001-00221, April 18, 2001.

${ }^{11}$ W. R. Wilmarth, J. T. Mills, and V. H. Dukes, "Results of Sorption/Desorption Experiments with IONSIV ${ }^{\circledR}$ IE-911 Crystalline Silicotitanate," WSRC-TR-2000-00394, January 24, 2001.
} 